\title{
Association of iron and vitamin A status with birth weight and anaemia among 6 month old infants in an urban population of Sri Lanka
}

\author{
Vithanage Pujitha Wickramasinghe ${ }^{1^{*}}$, Pulani Lanerolle ${ }^{2}$, Carukshi Arambepola ${ }^{3}$, Tharanga \\ Thoradeniya ${ }^{2}$, Dhanushka Mendis ${ }^{1}$ and Thilini Dinesha ${ }^{1}$ \\ ${ }^{\prime}$ Department of Paediatrics, Faculty of Medicine, University of Colombo, Kynsey Road, Colombo 08. \\ ${ }^{2}$ Department of Biochemistry and Molecular Biology, Faculty of Medicine, University of Colombo, Kynsey Road, Colombo 08. \\ ${ }^{3}$ Department of Community Medicine, Faculty of Medicine, University of Colombo, Kynsey Road, Colombo 08.
}

\begin{abstract}
Iron and vitamin A deficiencies are the commonest nutrition related problems in childhood, leading to severe health consequences. The objective of this study was to assess the relationship of iron and vitamin A status with birth weight and anaemia at 6 months of age of Sri Lankan infants. Ninety six healthy infants, aged $6-6.5$ months, were recruited from two Well-Baby Clinics in the Colombo Municipal Council area. Anthropometric parameters were assessed and an interviewer administered questionnaire was used to obtain data on their basic characteristics and feeding practices. Haemoglobin, serum ferritin, and retinol concentrations were estimated. The mean concentrations (CI) of haemoglobin, serum ferritin and serum retinol at 6 months were $11.2 \mathrm{~g} / \mathrm{dL}$ (95 \% CI 9.0, 13.3), $15.5 \mu \mathrm{g} / \mathrm{L}(95 \%$ CI 11.0, 20.0) and $34.8 \mu \mathrm{g} / \mathrm{dL}$ (95\% CI 19.3, 50.3 ), respectively. The prevalence of anaemia (haemoglobin $<$ $11 \mathrm{~g} / \mathrm{dL})$ was $43.0 \%(95 \%$ CI 33, 53), while iron deficiency (serum ferritin $<12 \mu \mathrm{g} / \mathrm{L}$ ) was $36.8 \%$ (95\% CI 27, 47). Both were relatively high. In contrast, only one child had vitamin A deficiency (serum retinol $<20 \mu \mathrm{g} / \mathrm{dL}$ ). A significantly higher prevalence of anaemia (47 versus $41 \%$ ) and lower serum ferritin $[11.5$ (95 \% CI 6.4, 16.6) versus 15.8 (95\% CI $11.5,20.1) \mu \mathrm{g} / \mathrm{L}]$ was seen among low birth weight infants compared to normal birth weight infants. The prevalence of iron deficiency was higher among anaemic infants compared to non-anaemic infants (49 versus $29 \%$ ), and among low birth weight infants compared to normal weight infants (60 versus $33 \%)$. However, these differences were not significant ( $p>$ $0.05)$. Although anaemia and iron deficiency were observed in these infants, vitamin A deficiency was not observed. Starting iron supplementation at six months could be beneficial while vitamin A supplementation programme needs re-evaluation.
\end{abstract}

Keywords: Anaemia, exclusive breast feeding, infant, iron deficiency, vitamin A deficiency.

\section{INTRODUCTION}

Iron and vitamin $\mathrm{A}$ are essential micronutrients that coordinate a range of physiological functions. They become even more important among infants, where growth and development occurs at a rapid pace. The persistence of iron deficiency and vitamin A deficiency among infants despite the introduction of infant and young child feeding (IYCF) guidelines is a cause for concern. Iron deficiency (ID) characterised by the clinical signs of deficiency such as poor feeding, retarded growth and development, increased infection, and absence of mobilisable iron stores, is the major cause of anaemia in children. There is strong evidence that iron deficiency anaemia (IDA) adversely affects cognitive performance, behaviour and physical growth of infants (Baker \& Frank, 2010). The link between vitamin A and iron has been demonstrated through early studies, showing improvement of iron status with vitamin A supplementation (Bloem, 1995). More recently, vitamin A has shown to have a role in iron homeostasis through hepcidin (Arruda et al., 2009; Citelli et al., 2012). While vitamin A plays a significant role in growth and development, vision, reproduction, cellular communication and immune function, the leading consequence of vitamin A deficiency (VAD) is preventable blindness in children and increased morbidity and mortality from respiratory and diarrhoeal infections (WHO, 2002; 2011a; Rice et al., 2004). Despite global advances in infant nutrition, high prevalence rates are still documented worldwide for both iron and vitamin A deficiencies. In Sri Lanka, $57.6 \%$ of infants in the second

*Corresponding author (pujithaw@yahoo.com) 
six months of life and $38.3 \%$ of children in their second year of life were anaemic according to the national survey of 2003 (Piyasena \& Mahamithawa, 2003). The National Nutrition and Micronutrient Survey conducted in 2012 showed that ID was $45.6 \%$ (95\% CI 39.7, 51.6) and $47.2 \%(95 \%$ CI 43.8, 50.6) in 6-11 month old infants and $12-23$ month old children, respectively (Jayatissa et al., 2014). IDA in the second six months of life was shown to be $19.7 \%$ and in the second year of life, $13.6 \%$. Compared to older age groups these values were statistically significantly higher (Jayatissa et al., 2014). Furthermore, about a third of pregnant women are anaemic, indicating the potential risk of reduced iron stores in the infant (Piyasena \& Mahamithawa, 2003). National data on vitamin A status in 1996 reported $35 \%$ VAD among 6 - 24 month old infants and a similar rate in older children based on serum retinol levels $(<20 \mu \mathrm{g} / \mathrm{dL})$ (MRI, 1998).

A term infant with a normal birth weight is expected to have adequate iron stores until 4-6 months of age. However, low birth weight, prematurity and maternal iron deficiency could compromise the iron stores a child is born with. In such cases of exclusively breast fed infants born with low iron stores, breast milk may not be an adequate source of iron until the commencement of complementary feeding (WHO, 2003a). This places greater emphasis on the iron content of complementary food and/or supplementation for ensuring adequate iron nutrition. In contrast, in the case of infants born with relatively low body stores of vitamin $\mathrm{A}$, breast milk of well-nourished mothers provides the best source of vitamin A for the infant. However, the vitamin A content of breast milk is affected by the nutritional status of the mother (Turner et al., 2013). Sri Lanka adopts the World Health Organisation (WHO, 2003b) recommendation of exclusive breast feeding in the first six months of life. Yet, Sri Lanka has a high prevalence of under-nutrition among adolescent girls and mothers, with infants of these under-nourished mothers being at a higher risk of developing iron and vitamin A deficiency (Piyasena \& Mahamithawa, 2003). A combination of maternal malnutrition and breast feeding on demand beyond the stipulated period of exclusive breast feeding, are likely factors for poor vitamin $\mathrm{A}$ and iron nutrition in infants.

Based on a vitamin A prevalence study among 6-60 month old children, the Ministry of Health and Nutrition initiated supplementation of children at 9, 18 and 36 months of age with mega dose vitamin A. Despite a high coverage rate $(84.8 \%)$ (Jayatissa \& Gunathilaka, 2006), the programme did not show a significant improvement in the vitamin A status of 6-60 month old children (Jayatissa \& Gunathilaka, 2006). Thereafter, the guidelines were revised to incorporate mega dose supplementation (200,000 IU) to postpartum mothers, with $100,000 \mathrm{IU}$ (half the WHO recommendation) to 6-60 month old infants at 6 monthly intervals (Vitamin A mega dose supplementation - Revised schedule. Circular Number: 01 - 05/2009 Ministry of Health, Sri Lanka). Concerns have been raised regarding both its usefulness and safety that cannot be supported nor refuted due to the absence of adequate country specific data. Although iron supplementation for pregnant and lactating women was in place for some time, iron supplementation for infants, school children and adolescents started recently. There is a void in country specific data, which has potential to inform the designing of effective programmes related to iron and vitamin A status. This study is an effort to fill this void and aims at determining the iron and vitamin A status of six month old infants living in an urban area of Sri Lanka, and describing the relationship with their anaemic status and birth weight. This paper reports the baseline data from a follow-up study of infants, designed to assess the impact of iron and vitamin A supplementation after six months.

\section{METHODOLOGY}

\section{Study design and subjects}

A total of 96 term singleton healthy infants, within 2 wks of completion of 6-months of age were recruited to the study from Well-Baby Clinics in the Colombo Municipal Council area during September 2012 to December 2013. Premature children and children having congenital defects or acute illnesses within the last $2 \mathrm{wks}$ prior to recruitment were excluded. The sample size calculated for the main study was 93 infants to detect a $57 \%$ reduction in iron deficiency following supplementation among children at 1 year (Piyasena \& Mahamithawa, 2003). The same sample size had adequate information to detect an estimated prevalence of $19.7 \%$ IDA among 6 months old babies (Jayatissa et al., 2014), with 0.08 precision and a $Z$ value of 1.96 at $5 \%$ level of significance. The sample was also able to detect a significant association between the ID status and anaemia at 6 months of age, based on 0.523 probability of ID among anaemic children (Jayatissa et al., 2014), 2.5 anticipated odds ratio for ID, $95 \%$ confidence level and $20 \%$ precision (Lwanga \& Lemeshow, 1991).

The mothers of these infants were on micronutrient supplementation as recommended by the national maternal and child health programme. They received daily supplementation containing $60 \mathrm{mg}$ of elemental iron, $1 \mathrm{mg}$ of folic acid, $100 \mathrm{mg}$ of vitamin $\mathrm{C}$ and $300 \mathrm{mg}$ of calcium (as calcium lactate) from $12 \mathrm{wk}$ period of 
amonerrhoea through delivery till 6 months postpartum, and the postpartum vitamin A mega dose (200,000 IU) at time of discharge from hospital after delivery (Antenatal Care General Circular- 02-85/2014, Ministry of Health, Sri Lanka). Low birth weight infants of the study group were on iron supplementation as per the national guidelines. The infants were recruited to the study before they received vitamin A mega dose at 6 months.

\section{Ethical considerations}

The study was conducted according to the protocol approved by the Ethics Review Committee of the Faculty of Medicine, University of Colombo, Sri Lanka. The study procedure was explained in detail and written informed consent was obtained from all parents/ caregivers.

\section{Data collection}

Interview based pre-tested questionnaires were administered by medical doctors to collect data on the socio-economic status, feeding practices, pre/post medical history, supplementations of the mother, $24 \mathrm{~h}$ dietary recall of infants and any episodes of respiratory tract infection (RTI) and diarrhoeal diseases at baseline (recruitment). Exclusive breast feeding was defined as feeding/having been fed nothing other than breast milk. Episodes of RTI was defined as an illness with upper respiratory symptoms and signs lasting for more than $48 \mathrm{~h}$ with or without fever, and diarrhoeal illness with watery loose stools (which is free flowing) more than 3 bouts per day lasting for more than $48 \mathrm{~h}$ (excluding frequent passage of formed stools or pasty stools as seen in breast fed babies).

Growth parameters; weight, length and occipital frontal circumference (OFC) at birth were obtained from the child health developmental record. The same parameters were also measured at recruitment by a trained research assistant following standard protocols. Birth weight was classified as low if it was $<2500 \mathrm{~g}$.

\section{Laboratory assessments}

A venous blood sample $(5 \mathrm{~mL})$ was obtained from each infant by an experienced phlebotomy nurse in a dark room that was not lit by direct sun or artificial light. An aliquot of anticoagulated blood was stored in ice during transportation and used for haemoglobin estimation within 4 hrs of collection. Estimation of haemoglobin was done by the cyanmethaemoglobin photometric method. The remainder of the blood was transferred to a plain centrifuge tube covered with aluminium foil to protect from light, and left at room temperature in a covered box to clot before storing in ice for transportation. The serum was separated by centrifuging at $3000 \mathrm{~g}$ for $10 \mathrm{~min}$ and stored at $-20{ }^{\circ} \mathrm{C}$ until analysed within 3 months. Serum retinol was assessed by the method recommended by the International Vitamin A Consultative Group (IVACG, 1982) using reversed phase-high performance liquid chromatography (HPLC). External quality control sera were used for the serum retinol assay. Serum ferritin was estimated based on the peroxidase-conjugated enzyme linked immunosorbent assay (ELISA) method, using human ferritin enzyme immunoassay test kit (Diagnostic Automation, INC, USA). Qualitative determination of C-reactive protein (CRP) was carried out using a CRP latex test kit (Randox Laboratories Ltd.). All biochemical assays were carried out according to the standard quality control procedures at the Department of Biochemistry and Molecular Biology, and haemoglobin estimation was carried out at the Department of Clinical Medicine, Faculty of Medicine, University of Colombo, Sri Lanka.

Anaemia was defined as haemoglobin $<11 \mathrm{~g} / \mathrm{dL}$ (WHO, 2011b). Iron deficiency and vitamin A deficiency were defined as serum ferritin $<12 \mu \mathrm{g} / \mathrm{L}$ (WHO, 2011c) and serum retinol $<20 \mu \mathrm{g} / \mathrm{dL}$, respectively (WHO, 2011d).

\section{Statistical analysis}

The data were analysed on SPSS version 20 statistical software (SPSS Inc., Chicago, IL, USA). One-Sample Kolmogorov-Smirnov was used to test the distribution of variables. Demographic and anthropometric data were presented with mean and standard deviations and biochemical data presented as mean with $95 \%$ confidence intervals (CI). Chi-square test was used to test significant differences of iron status between anaemic and non-anaemic groups, and between normal and low birth weight groups at $5 \%$ level of significance.

\section{RESULTS}

\section{Demographic and socio-economic characteristics of the infants}

A total of 96 infants within 2 weeks of completion of 6 months were recruited to the study. Their mean $\pm \mathrm{SD}$ age was $194 \pm 17$ days. The sex distribution of the infants was 54 boys and 42 girls. As indicated in Table 1, baseline characteristics of the infants showed that 53 families of infants $(55 \%)$ had a monthly income less than LKR $25,000 /=$. This is indicative of their low economic level although it is well above the poverty level. While parents were able to read and write, most mothers $(92.7 \%)$ and fathers $(93.7 \%)$ had completed secondary or a higher 
level of education, which reflects the high literacy in Sri Lanka. All the mothers of infants had received postpartum vitamin A mega dose. Intake/compliance of intake of supplements (iron, folate and calcium) during pregnancy and post-partum by mothers were verified and compliance was satisfactory.

Table 1: Demographic and socio-economic characteristics of the infants $(\mathrm{N}=96)$

\begin{tabular}{ll}
\hline Characteristic & \\
\hline $\begin{array}{l}\text { Age in days (mean } \pm \text { SD) } \\
\text { Gender (n, \%) }\end{array}$ & $194 \pm 17$ \\
$\quad$ Boy & $54(56.3)$ \\
$\quad$ Girl & $42(43.8)$ \\
Family income (n, \%) & \\
$\quad<$ Rs 25,000 & $53(55.2)$ \\
$>$ Rs 25,000 & $43(44.8)$ \\
Level of education of mother (n, \%) & \\
$\quad$ No schooling & $01(1.0)$ \\
$\quad$ Primary & $06(6.3)$ \\
Secondary & $43(44.8)$ \\
$\quad$ Collegiate & $29(30.2)$ \\
Tertiary & $17(17.7)$ \\
Level of education of father $(\mathrm{n}, \%)$ & \\
$\quad$ No schooling & $01(1.1)$ \\
Primary & $05(5.3)$ \\
Secondary & $40(42.1)$ \\
Collegiate & $32(33.7)$ \\
Tertiary & $17(17.9)$ \\
Exclusively breast fed (n, \%) & $24(25)$ \\
\hline
\end{tabular}

Table 2: Distribution of haemoglobin, serum ferritin and vitamin A

\begin{tabular}{cc}
\hline & $\mathrm{N},(\%)$ \\
\hline Haemoglobin $(\mathrm{g} / \mathrm{dL})$ & \\
$>11$ & $54(57.4)$ \\
$10-10.9$ & $28(29.8)$ \\
$<10$ & $12(12.8)$ \\
Serum ferritin $(\mu \mathrm{g} / \mathrm{L})$ & \\
$<12$ & $35(38.4)$ \\
$12-19.9$ & $22(24.2)$ \\
$>20$ & $34(37.4)$ \\
Serum vitamin A $(\mu \mathrm{g} / \mathrm{dL})$ & \\
$<20$ & $01(1.1)$ \\
$20-29.9$ & $27(29.7)$ \\
$>30$ & $63(69.2)$ \\
\hline
\end{tabular}

Data available for 91 infants' serum ferritin and vitamin A and 94 infants' haemoglobin

\section{Anthropometric, biochemical and clinical characteristics}

Anthropometric, biochemical and clinical characteristics of the infants at 6 months are described in Table 2. A third of the sample was wasted, and 12 children were underweight and 4 were stunted.

Table 2 shows the distribution of vitamin A, iron and haemoglobin categorised according to commonly used serum cutoff values. Although vitamin A deficiency was not a problem, there were 27 infants $(28.4 \%)$ having insufficiency $(20-29.9 \mu \mathrm{g} / \mathrm{dL})$. There were $23 \%$ with serum ferritin levels between $12-19.9 \mu \mathrm{g} / \mathrm{L}$. Of those who were anaemic, 12 children had haemoglobin levels less than $10 \mathrm{~g} / \mathrm{dL}$. CRP levels were within normal limits.

The mean haemoglobin concentration was $11.2 \mathrm{~g} / \mathrm{dL}$ (95\% CI 9.0, 13.3), while 40 (42.5\%) infants were anaemic (haemoglobin $<11.0 \mathrm{~g} / \mathrm{dL}$ ) (Table 3). The mean serum ferritin concentration was $15.5 \mu \mathrm{g} / \mathrm{L}(95 \%$ CI 11.0, 20.0), while 35 (37.2\%) infants showed iron deficiency (serum ferritin $<12 \mu \mathrm{g} / \mathrm{L}$ ). The mean serum retinol concentration was $34.8 \mu \mathrm{g} / \mathrm{dL}$ (95\% CI 19.3, 50.3). Only one infant had serum retinol $<20 \mu \mathrm{g} / \mathrm{dL}$ suggestive of vitamin A deficiency. Ten infants had respiratory tract infections within the first 6 months, while none had diarrhoeal diseases. The micronutrient status between normal and under-nourished groups did not show significant differences. However, when compared between low and normal birth weight infants, haemoglobin, serum ferritin and vitamin A were low in the low birth weight group although they were not statistically significant (Table 3 ).

As shown in Table 4, $51 \%$ of the anaemic infants were iron deficient, while $29 \%$ of the non anaemic infants were iron deficient at 6 months. Furthermore, about one third of the normal birth weight infants and about $60 \%$ of the low birth weight infants were iron deficient despite iron supplementation given through the national scheme. None of the relationships were statistically significant $(\mathrm{p}>0.05)$. In contrast, the prevalence of anaemia at 6 months was marginally higher ( $47 \%$ vs $41 \%$; $p>0.05)$, and the iron status was marginally lower (mean $\pm \mathrm{SD}$; $11.5 \pm 2.6 v s 15.8 \pm 2.2 \mu \mathrm{g} / \mathrm{L} ; \mathrm{p}>0.05$ ) in low birth weight infants compared to the infants with normal birth weight.

Approximately $25 \%$ of the babies were exclusively breast fed up to the completion of 6 months of age. Complementary feeding was initiated before 6 months of age without any medical advice, in over $73.0 \%$ of 
the infants. The commonest foods/fluids given during the first six months were formula milk $(64.2 \%)$, rice based food $(81.1 \%)$, fruit juices $(65.3 \%)$ and water $(62.1 \%)$. Reasons quoted for stopping exclusive breast feeding were; the perception of 'deficient breast milk' (26.9\%), giving formula milk considered to be the norm (30\%) and being away from the baby (26.9\%). However, although not exclusively, all infants in the study group

Table 3: Distribution of anthropometric, clinical and biochemical parameters of the study group at 6 months of age according to nutritional status and birth weight

\begin{tabular}{|c|c|c|c|}
\hline & \multirow{2}{*}{$\begin{array}{l}\text { Total population } \\
\qquad(\mathrm{n}=96)\end{array}$} & \multicolumn{2}{|c|}{ Categorised according to nutritional status } \\
\hline & & $\begin{array}{l}\text { Normal } \\
(\mathrm{n}=66)\end{array}$ & $\begin{array}{l}\text { Under-nutrition }^{ \pm} \\
\qquad(\mathrm{n}=30)\end{array}$ \\
\hline \multicolumn{4}{|l|}{ Anthropometry (mean $\pm \mathrm{SD})$} \\
\hline Weight $(\mathrm{kg})$ & $7.1 \pm 1.0$ & $7.4 \pm 0.9$ & $6.4 \pm 0.12 *$ \\
\hline Weight Z-score & $-0.72 \pm 1.1$ & $-0.37 \pm 1.0$ & $-1.5 \pm 1.1 *$ \\
\hline Height $(\mathrm{cm})$ & $68.1 \pm 3.4$ & $67.8 \pm 1.0$ & $68.5 \pm 3.7$ \\
\hline Height Z-score & $0.61 \pm 1.5$ & $0.38 \pm 1.4$ & $0.93 \pm 1.7$ \\
\hline \multicolumn{4}{|l|}{ Biochemical investigations } \\
\hline Haemoglobin $(\mathrm{g} / \mathrm{dL})$ & $11.2(9.0,13.4)$ & $11.3(9.1,13.5)$ & $10.9(8.5,13.3)$ \\
\hline Serum ferritin $(\mu \mathrm{g} / \mathrm{L})$ & $15.5(11.0,20.0)$ & $15.1(10.8,19.4)$ & $18.5(13.6,20.4)$ \\
\hline Serum vitamin $\mathrm{A}(\mu \mathrm{g} / \mathrm{dL})$ & $34.8(19.2,50.3)$ & $34.4(19.7,49.1)$ & $35.7(18.6,52.8)$ \\
\hline Anaemia (Haemoglobin < 11 g/dL) & $40(42.5 \%)$ & $23(35 \%)$ & $17(57 \%)$ \\
\hline Iron deficiency (Serum ferritin $<12 \mu \mathrm{g} / \mathrm{L}$ ) & $35(37.2 \%)$ & $25(38 \%)$ & $10(33 \%)$ \\
\hline Vitamin A deficient (Vitamin $\mathrm{A}<20 \mu \mathrm{g} / \mathrm{dL}$ ) & $01(1.1 \%)$ & - & $01(1.1 \%)$ \\
\hline
\end{tabular}

Categorised according to birth weight

\begin{tabular}{lcc} 
& $\begin{array}{c}\text { Normal } \\
(\mathrm{n}=76)\end{array}$ & $\begin{array}{c}\text { Low } \\
(\mathrm{n}=17)\end{array}$ \\
\hline Haemoglobin $(\mathrm{g} / \mathrm{dL})$ & $11.3(9.1,13.5)$ & $10.8(8.6,13.0)$ \\
Serum ferritin $(\mu \mathrm{g} / \mathrm{L})$ & $17.4(13.1,21.7)$ & $11.5(6.4,16.6)$ \\
Serum vitamin A $(\mu \mathrm{g} / \mathrm{dL})$ & $35.1(20.0,50.2)$ & $34.6(16.0,43.2)$ \\
Anaemia $($ Haemoglobin $<11 \mathrm{~g} / \mathrm{dL})(\mathrm{n})$ & 32 & 6 \\
Iron deficiency $($ Serum ferritin $<12 \mu \mathrm{g} / \mathrm{L})$ & 25 & 10 \\
Vitamin A deficient $($ Vitamin $\mathrm{A}<20 \mu \mathrm{g} / \mathrm{dL})$ & - & 1
\end{tabular}

\begin{tabular}{lcc}
\hline & $\begin{array}{c}\text { Categorised according to duration of } \\
\text { exclusive breast feeding }\end{array}$ \\
& $\begin{array}{c}6 \text { months } \\
(\mathrm{n}=22)\end{array}$ & $\begin{array}{c}<\text { months } \\
(\mathrm{n}=69)^{\ddagger}\end{array}$ \\
\hline Haemoglobin $(\mathrm{g} / \mathrm{dL})$ & $11.1(8.9,13.3)$ & $11.2(9.0,13.4)$ \\
Serum ferritin $(\mu \mathrm{g} / \mathrm{L})$ & $15.1(11.8,18.4)$ & $15.8(11.1,20.5)$ \\
Serum vitamin A $(20 \mu \mathrm{g} / \mathrm{dL})$ & $36.2(20.3,52.1)$ & $34.6(20.3,50.5)$ \\
Anaemia $($ Haemoglobin $<11 \mathrm{~g} / \mathrm{dL})$ & 10 & 28 \\
Iron deficiency $($ Serum ferritin $<12 \mu \mathrm{g} / \mathrm{L})$ & 8 & 27 \\
Vitamin A deficient $($ Vitamin $\mathrm{A}<20 \mu \mathrm{g} / \mathrm{dL})$ & 0 & 1 \\
\hline
\end{tabular}

Data available for 91 infants' serum ferritin and vitamin A and 94 infants' haemoglobin concentration as mean and $95 \% \mathrm{CI}$

$* \mathrm{p}<0.05$ when compared normal children with MAM/SAM

${ }^{ \pm}$Under-nutrition defined as weight for height $<-2 \quad$ Z-score

* Data not available for the whole populations 
were breast fed. There was no significant difference in the haemoglobin and serum ferritin levels between the exclusively breast fed and non-exclusively breast fed groups at six months. Respiratory tract infections although noted, were mild with no significant morbidity.

Table 4: Iron status in relation to haemoglobin and birth weight of the infants at 6 months \pm 2 weeks of age

\begin{tabular}{lcccc}
\hline & \multicolumn{2}{c}{ Haemoglobin } & \multicolumn{2}{c}{ Birth weight } \\
Iron status & $\begin{array}{c}\text { Normal } \\
(\mathrm{n}, \%)\end{array}$ & $\begin{array}{c}\text { Anaemia } \\
(\mathrm{n}, \%)\end{array}$ & $\begin{array}{c}\text { Normal } \\
(\mathrm{n}, \%)\end{array}$ & $\begin{array}{c}\text { Low } \\
(\mathrm{n}, \%)\end{array}$ \\
\hline Normal & $37(71 \%)$ & $18(49 \%)$ & $50(67 \%)$ & $7(41 \%)$ \\
Deficient & $15(29 \%)$ & $19(51 \%)$ & $24(33 \%)$ & $10(59 \%)$ \\
Total & $52(100 \%)$ & $37(100 \%)$ & $74(100 \%)$ & $17(100 \%)$ \\
\hline
\end{tabular}

Data is available on serum ferritin for 91 and haemoglobin for 94 infants

\section{DISCUSSION}

Compared with the national prevalence of $34 \%$ anaemia among 6 to 11 month old infants, a higher proportion of infants in the study population were anaemic (42.5\%) (Jayatissa et al., 2012). Iron deficiency was observed in $37.2 \%$ of the infants at 6 months of age in this study population. Owing to less precision in the calculated sample size, data on the prevalence of ID requires cautious interpretation when comparing it with the national data. In populations, which are considered vulnerable with high prevalence of IDA in young children, supplementation is recommended as the evidence is strong for its benefits (Baker \& Frank, 2010; Lozoff et al., 2012). In deciding the best public health measure for a population, evidence for not only prevalence, but also feeding practices as documented in this study are needed.

The European Society for Paediatric Gastroenterology Hepatology and Nutrition (ESPGHAN) committee on nutrition concluded that there is no convincing evidence that iron supplements should be provided to normal birth weight, exclusively breast fed infants during the first 6 months in populations such as Europe, where IDA prevalence is low. However, even in Europe supplementation in those with deficiency is recommended (Domellof et al., 2014; Eussen et al., 2015). This requires global screening, but even in some states of USA, screening and its ensuing treatment has been proved difficult to achieve (Biondich et al., 2006). Dewey et al. (1998) recommended the use of iron drops for infants with a birth weight of less than $3.0 \mathrm{~kg}$.
The high prevalence of ID in the present study as well as national data (Jayatissa et al., 2014), minimising both ID and IDA becomes a priority. A large scale study in the USA of paediatric care settings highlights that although infants are screened, that information does not result in better care for the most part (Biondich et al., 2006). The decision to screen and treat or for blanket cover rests on the cost effectiveness in terms of reduction of prevalence of IDA or ID and its consequences. Evidence for baseline factors is essential to provide a base to begin interventions. As in the national survey (Jayatissa et al., 2014), breast feeding was high in the study population with all infants being breast fed. However, the findings indicate 2 factors; the rate of exclusive breast feeding for 6 months is very low in the population, and there were no significant differences in the iron status between the six month exclusively breast fed and the non-exclusively breast fed groups, where the latter group of infants were fed for varying durations less than 6 months. Hence the overall high prevalence in both the breast fed and the non-breast fed groups would indicate that for Sri Lanka, supplementation is likely to benefit both those who meet and do not meet the breast feeding guidelines. The WHO highlights the possible need for supplementation of exclusively breast fed infants with medicinal iron during exclusive breast feeding period in those even if their birth weights were normal, but mothers were iron deficient perinatally (PAHO/WHO 2001). Therefore, considering these facts and the high prevalence of maternal undernutrition in Sri Lanka (Piyasena \& Mahamithawa, 2003) together with our findings of the high prevalence of iron deficiency and anaemia in infants at the age of 6 months, it is necessary to consider iron supplementation for infants during or immediately after exclusive breast feeding.

The American Academy of Paediatrics (AAP) recommends universal screening of all infants at 1 year using haemoglobin (Baker \& Frank, 2010). However, haemoglobin is not the ideal tool for screening for iron status as only half of those who were ID in the present study were anaemic. Domellof et al. (2001) showed that iron supplementation from 4 to 9 months or 6 to 9 months significantly reduced iron deficiency anaemia in breast fed babies. Therefore, in a Sri Lankan context blanket supplementation (without screening) of all infants at least at 6 months of age would be important, as screening tools such as haemoglobin would not indicate the true magnitude of the problem. Furthermore, despite supplementation being provided to low birth weight infants through the national scheme, about half of them were still ID at 6 months of age. These infants would need both continued supplementation and iron rich 
complementary feeding. The present study also showed that only about a half of those with anaemia had iron deficiency and that majority of the infants were started on complementary feeding without guidance, indicating the possibility of poor micronutrient status in addition to iron. This could be the reason that the micronutrient and macronutrient deficiency status did not show a parallel. Higher number of iron deficient infants among normally nourished children than under-nourished could be due to the higher intake of calorie rich food but deficient in micronutrients. This highlights the need for early guidance on the preparation of complementary food rich in iron and other micronutrients.

The age range of $6-59$ months has been identified in previous studies to be the greatest risk period for vitamin A deficiency (Rice et al., 2004; WHO, 2011a). Despite the 2006 national vitamin A survey prevalence rates of $29 \%$ of under-five children being vitamin A deficient (Jayatissa \& Gunathilaka, 2006), the present study population had sufficient serum vitamin A concentrations at 6 months in almost all study subjects. Infants are born with negligible liver stores of vitamin $A$ and evidence suggests that if the mother receives the single postpartum mega dose of vitamin A, it is adequate during lactation and the infants' risk of developing vitamin A deficiency is low (WHO, 2011e). This could be a possible explanation for the sufficient serum vitamin A concentrations seen among the infants in the present study who were sampled before they were given a mega dose at 6 months.

Vitamin A supplementation can reduce diarrhoea specific mortality in $6-59$ month old infants (Imdad, 2010). RTI but not diarrhoea was observed among the study populations and the overcrowded urban communities could be the explanation rather than micronutrient deficiencies. A limitation in this study was that the population was not generalisable due to its sampling frame, and not nationally representative, yet the similarity of the general characteristics to the national data makes the findings relevant.

\section{CONCLUSION}

Iron deficiency and iron deficiency anaemia were common in 6 months old infants. This suggests that iron supplementation at least at 6 months and increasing iron rich foods from the inception of complementary feeding is important to prevent ID and IDA in infants. The timing and duration of iron supplementation needs to be decided based on the response as well as on the establishment of intake of complementary food with adequate intake of iron rich food. Adequate vitamin A levels could be due to vitamin A supplementation of the lactating mothers immediately after delivery and it needs to be strengthened. Complementary feeding guides have to be strengthened to improve iron, vitamin $\mathrm{A}$ and perhaps other micronutrients in infants.

\section{Acknowledgement}

The authors thank the parents and their infants for participating in the study and the staff of the Well-Baby Clinics in the Colombo Municipal Council area. Thanks are due to Ms M.S.K. Rabindrakumar for managing the data, and Thisira Andrahennadi and R.P.N. Priyanthi of the Department of Biochemistry and Molecular Biology, Faculty of Medicine, University of Colombo for technical assistance in HPLC estimation of vitamin A and serum ferritin estimation. The study was funded by a National Science Foundation grant (RG/2011/HS/14).

\section{REFERENCES}

1. Arruda S.F., Siqueira E.M. \& de Valência F.F. (2009). Vitamin A deficiency increases hepcidin expression and oxidative stress in rat. Nutrition 25(4): $472-478$.

DOI: https://doi.org/10.1016/j.nut.2008.11.030

2. Baker R.D. \& Frank R. (2010). Clinical report: diagnosis and prevention of iron deficiency and iron deficiency anaemia in infants and young children $(0-3$ years of age). Pediatrics 126(5): 1040 - 1050.

DOI: https://doi.org/10.1542/peds.2010-2576

3. Biondich P.G., Downs S.M., Carroll A.E. \& Laskey A.L. (2006). Shortcomings in infant iron deficiency screening methods. Pediatrics 117: 290 - 294.

DOI: https://doi.org/10.1542/peds.2004-2103

4. Bloem M.W. (1995). Interdependence of vitamin A and iron: an important association for programmes of anaemia control. Proceedings of the Nutrition Society 54(2): $501-508$.

DOI: https://doi.org/10.1079/PNS19950018

5. Citelli M., Bittencourt L.L., da Silva S.V., Pierucci A.P. \& Pedrosa C. (2012). Vitamin A modulates the expression of genes involved in iron bioavailability. Biological Trace Element Research 149(1): 64 - 70.

DOI: https://doi.org/10.1007/s12011-012-9397-6

6. Dewey K.G., Cohen R.J., Rivera L.L. \& Brown K.H. (1998). Effects of age of introduction of complementary food on iron status of breast-fed infants in Honduras. American Journal of Clinical Nutrition 67(5): 878 - 884.

7. Domellof M., Cohen R.J., Dewey K.G., Hernell O., Rivera L.L. \& Lonnerdal B. (2001). Iron supplementation of breast-fed Honduran and Swedish infants from $4-9$ months of age. Journal of Pediatrics 138(5): $679-687$. DOI: https://doi.org/10.1067/mpd.2001.112895

8. Domellof M. et al. (12 authors) (2014). Iron 
requirements of infants and toddlers. Position paper for ESPGHAN committee on nutrition. Journal of Pediatric Gastroenterology and Nutrition 58(1): 119 - 129. DOI: https://doi.org/10.1097/MPG.0000000000000206

9. Eussen S., Alles M., Uijterschout L., Brus F. \& van der Horst-Graat J. (2015). Iron intake and status of children aged 6-36 months in Europe: a systematic review. Annals of Nutrition and Metabolism 66: 80 - 92 . DOI: https://doi.org/10.1159/000371357

10. Imdad A., Herzer K., Mayo-Wilson E., Yakoob M.Y. \& Bhutta Z.A. (2010). Vitamin A supplementation for preventing morbidity and mortality in children from 6 months to 5 years of age. Cochrane Database of Systematic Review (12): CD008524. DOI: https://doi.org/10.1002/14651858.cd008524.pub2

11. International Vitamin A Consultative Group (IVACG) (1982). Biochemical Methodology for the Assessment of Vitmain A status. The Nutrition Foundation, New York, USA.

12. Jayatissa R. \& Gunathilaka M.M. (2006). Vitamin A Nutrition Status in Sri Lanka. Medical Research Institute, P.O. Box 527, Dr Danister De Silva Mawatha, Colombo 08.

13. Jayatissa R., Gunathilaka M.M., Herath P. \& Fernando D.N. (2012). National Nutrition and Micronutrient Survey. Part I: Anaemia among Children Aged 6-59 Months and Nutritional Status of Children and Adults. Ministry of Health and UNICEF Sri Lanka.

14. Jayatissa R., Gunathilaka M.M., Herath P. \& Fernando D.N. (2014). National Nutrition and Micronutrient Survey. Part II. Iron, Zinc and Calcium Deficiency among Children Aged 6-59 Months. Ministry of Health and UNICEF Sri Lanka.

15. Lozoff B., Castillo M., Clark K.M. \& Smith J.B. (2012). Iron-fortified $v s$ low-iron infant formula: developmental outcome at 10 years. Archives of Pediatrics and Adolescent Medicine 166(3): 208 - 215.

DOI: https://doi.org/10.1001/archpediatrics.2011.197

16. Lwanga S.K. \& Lemeshow S. (1991). Sample Size Determination in Health Studies: a Practical Manual. World Health Organization, Geneva, Switzerland.

17. Medical Research Institute (MRI) (1998). Vitamin A Deficiency Status of Children in Sri Lanka 1995/1996. Medical Research Institute, P.O. Box 527, Dr Danister De Silva Mawatha, Colombo 08.

18. Pan American Health Organization (PAHO) and World Health Organization (WHO) (2001). Guiding Principles for Complementary Feeding of the Breastfed Child. World
Health Organization, Geneva, Switzerland.

19. Piyasena C. \& Mahamithawa A.M.A.S.B. (2003). Assessment of Anaemia Status in Sri Lanka. Medical Research Institute, P.O. Box 527, Dr Danister De Silva Mawatha, Colombo 08.

20. Rice A.L., West K.P. \& Black R.E. (2004). Vitamin A deficiency. Comparative Quantification of Health Risks. Global and Regional Burden of Diseases Attributable to Selected Major Risk Factors, volume 1 (eds. M. Ezzatti, A.D. Lopez, A. Rodgers \& C.J.L. Murray), pp. $211-256$. World Health Organization, Geneva, Switzerland.

21. Turner T., Burri B.J., Jamil K.M. \& Jamil M. (2013). The effects of daily consumption of b-cryptoxanthin-rich tangerines and b-carotene-rich sweet potatoes on vitamin $\mathrm{A}$ and carotenoid concentrations in plasma and breast milk of Bangladeshi women with low vitamin A status in a randomized controlled trial. American Journal of Clinical Nutrition 98(5): 1200 - 1208.

DOI: https://doi.org/10.3945/ajcn.113.058180

22. World Health Organization (WHO) (2002). Vitamin A. Human Vitamin and Mineral Requirements. Report of a Joint FAO/WHO Expert Consultation, pp. 87 - 107. Food and Agriculture Organization, Rome, Italy.

23. World Health Organization (WHO) (2003a). Guiding Principles for Complementary Feeding of the Breastfed Child. World Health Organization, Geneva, Switzerland.

24. World Health Organization (WHO) (2003b). Global Strategy for Infant and Young Child Feeding. World Health Organization, Geneva, Switzerland.

25. World Health Organization (WHO) (2011a). Vitamin A Supplementation in Infants and Children 6-59 Months of Age. World Health Organization, Geneva, Switzerland.

26. World Health Organization (WHO) (2011b). Haemoglobin Concentrations for the Diagnosis of Anaemia and Assessment of Severity. World Health Organization, Geneva, Switzerland.

27. World Health Organization (WHO) (2011c). Serum Ferritin Concentration for the Assessment of Iron Status and Iron Deficiency in Populations. World Health Organization, Geneva, Switzerland.

28. World Health Organization (WHO) (2011d). Serum Retinol Concentration for Determining the Prevalence of Vitamin A Deficiency in Populations. World Health Organization, Geneva, Switzerland.

29. World Health Organization (WHO) (2011e). Guideline: Vitamin A Supplementation in Postpartum Women. World Health Organization, Geneva, Switzerland. 